Wilfrid Laurier University

Scholars Commons @ Laurier

Kinesiology and Physical Education Faculty

Publications

Kinesiology and Physical Education

2010

\title{
The Adaptation Challenges and Strategies of Adolescent Aboriginal Athletes Competing Off Reserve
}

\author{
Robert J. Schinke \\ Laurentian University \\ Amy T. Blodgett \\ Laurentian University \\ Hope E. Yungblut \\ Laurentian University \\ Mark Eys \\ Wilfrid Laurier University, meys@wlu.ca \\ Randy C. Battochio \\ Laurentian University
}

See next page for additional authors

Follow this and additional works at: https://scholars.wlu.ca/kppe_faculty

Part of the Kinesiology Commons, and the Medicine and Health Sciences Commons

\section{Recommended Citation}

Schinke, R.J., Blodgett, A.T., Yungblut, H.E., Eys, M.A., Battochio, R. C., Wabano, M.J., Peltier, D., Ritchie, S., Pickard, P., \& Recollet-Saikonnen, D. (2010) The Adaptation Challenges and Strategies of Adolescent Aboriginal Athletes Competing Off Reserve, Journal of Sport \& Social Issues, 34(4), pp. 438-456.

This Article is brought to you for free and open access by the Kinesiology and Physical Education at Scholars Commons@ @aurier. It has been accepted for inclusion in Kinesiology and Physical Education Faculty Publications by an authorized administrator of Scholars Commons @ Laurier. For more information, please contact scholarscommons@wlu.ca. 


\section{Authors}

Robert J. Schinke, Amy T. Blodgett, Hope E. Yungblut, Mark Eys, Randy C. Battochio, Mary Jo Wabano, Duke Peltier, Stephen Ritchie, Patricia Pickard, and Danielle Recollet-Saikkonen 


\section{The Adaptation}

Challenges and Strategies of Adolescent Aboriginal

Athletes Competing

Off Reserve
Journal of Sport \& Social Issues

34(4) 438-456

(C) 2010 SAGE Publications Reprints and permission: http://www. sagepub.com/journalsPermissions.nav DOI: $10.1177 / 0193723510379993$ http://jss.sagepub.com

@SAGE

\author{
Robert J. Schinke', Amy T. Blodgett', \\ Hope E. Yungblut', Mark A. Eys', \\ Randy C. Battochio', Mary Jo Wabano ${ }^{3}$, \\ Duke Peltier', Stephen Ritchie', Patricia Pickard', \\ and Danielle Recollet-Saikonnen ${ }^{3}$
}

\begin{abstract}
Within the motivation literature, it has been indicated that athletes respond more effectively to sport's contextual challenges through effective adaptation skills. Fiske identified five core motives as facilitators of the adaptation process across cultures: belonging, understanding, controlling, self-enhancement, and trusting. Through a cultural sport psychology approach, the adaptation challenges and strategies of Canadian Aboriginal adolescent athletes from one community (Wikwemikong) are described as they traveled off reserve to compete in mainstream sporting events. Concurrently, Fiske's core motives are considered in relation to youth sport participants from the aforementioned Aboriginal community. Culture sensitive research methods among the Wikwemikong, including community meetings, talking circles (TCs), indigenous coding, and coauthoring, were employed in this article. Data are

\footnotetext{
'Laurentian University, Sudbury, Ontario, Canada

${ }^{2}$ Wilfrid Laurier University, Waterloo, Ontario, Canada

${ }^{3}$ Wikwemikong Unceded Indian Reserve, Manitoulin District, Ontario, Canada

Corresponding Author:

Robert J. Schinke, EdD, CSPA, B-24I Ben Avery Building, School of Human Kinetics, 935 Ramsey Lake Rd., Laurentian University, Sudbury, Ontario, Canada, P3E 2 C6

Email: rschinke@laurentian.ca
} 
reflected in three themes: (a) challenges pursuing sport outside of the Aboriginal community in advance of bicultural encounters, (b) challenging bicultural encounters in Canadian mainstream sport contexts, and (c) specific responses to racism and discrimination.

\section{Keywords}

sport, cultural sport psychology, qualitative research

During the last 5 years, through a line of inquiry known as cultural sport psychology (CSP), authors have challenged the status quo in applied and theoretical approaches to their field. Sport psychology has recently been considered as a domain generally reflecting White, mainstream values manifested in the ways sport scientists understand one's self and another. Consequently, some sport psychologists are now employing culturally reflexive approaches with clients and research participants in and through their work (see Fisher, Butryn, \& Roper, 2003; Ryba \& Wright, 2005; Schinke et al., 2008). The rationale behind proposed reconceptualizations of the field is that the challenges athletes encounter are sometimes uniquely their own, with proposed solutions that are in part cultural.

Among the challenges encountered by athletes from marginalized cultures are adaptation struggles such as when sport is pursued in unfamiliar cultural contexts. Adaptation refers to the process through which people from a given culture "understand their surroundings and [within these learn to] function competently" (Fiske, 2004, p. 25). Integrating a CSP (culturally reflexive) paradigm, we have considered the adaptation challenges and strategies of Canadian Aboriginal athletes from the Wikwemikong Unceded Indian Reserve as they traveled off reserve to pursue sport competitions in mainstream contexts. This manuscript is a collaborative effort among mainstream academics from a University and community coresearchers from Wikwemikong. The bicultural research team has worked together for a period of 5 years on two consecutive Social Science and Humanities Research Council of Canada (SSHRC) funded research projects pertaining to Aboriginal sport participation. As part of our most recent initiative aimed at the refinement of community sport programs to enhance youth sport opportunities in Wikwemikong (see Blodgett et al., 2008), community meetings and talking circles (TCs) were held to discuss three topics: (a) the role of family on youth sport participation on reserve, (b) the role of community on youth sport participation on reserve, and (c) pertaining to the immediate manuscript, the adaptation experiences (challenges and strategies) of reserve youth when they travel to compete in sport off reserve among the mainstream culture.

\section{Adaptation}

Adaptation and its associated conceptual frameworks were first introduced in reference to people challenged with life-threatening events. Referencing cancer patients, Taylor 
(1983) identified three cognitive strategies that contribute to effective adaptation. Meaning refers to efforts toward understanding one's context, mastery pertains to gaining a sense of control over one's situation, and self-enhancement refers to the need to preserve self-esteem. Recently, Fiske (2004) extended Taylor's work into a more elaborate classification system of adaptation core motives (i.e., strategies). The core motives include (a) understanding, (b) controlling, and (c) self-enhancement, which parallel Taylor's themes of meaning, mastery, and self-enhancement, respectively. Furthermore, Fiske added two relational aspects to adaptation: (d) belonging and (e) trust. The most recent motives (i.e., belonging, trust) are rooted in the belief that humans have an innate need to fit into their social contexts rather than functioning entirely as individuals in isolation. In terms of belonging, people seek to develop secure relationships within social groups, which help them garner effective support resources. Trusting refers to the sense of anticipatory faith bestowed on others to help manage or avoid adversities. Though frameworks regarding adaptation were developed for those overcoming life challenges such as physical illness, the examination of this concept has extended to sport.

\section{Adaptation in Sport}

Tenenbaum, Jones, Kitsantis, Sachs, and Berwick (2003) were among the first researchers to apply adaptation to sport. Using a case study methodology with elite cyclists, the authors identified stressors in the sporting environment and gauged athletes' emotional, mental, and physical responses to those stressors. Responses were then assessed in terms of failure or success adaptation. For the cyclists, effective adaptation strategies included positive affect, low levels of state anxiety, strong feelings of vigor and hope, clarity of thought, flexibility in relation to the sport environment, and a strong sense of social support. The strategy of remaining flexible regarding the sport environment matched Fiske's (2004) core motive of understanding, while maintaining low levels of anxiety affirmed the motive of controlling. In addition, self-enhancement was evident in the cyclists' needs to improve their physical performances, while belonging was ascertained through a sense of social support. Therefore, Tenenbaum et al. (2003) paralleled Fiske's adaptation core motives, at least with mainstream athletes in one sport.

Though CSP research is only in its infancy, the adaptation process has already been considered with minority athletes in mainstream sport and physical activity contexts, at first through informal means. For example, Hanrahan (2004) consulted with Australian Aborigine performing artists and found that they were shy in mainstream contexts while working on motivational strategies with her (Hanrahan is White, North American, middle class, and formally educated). To facilitate better relations, Hanrahan spoke of understanding Aborigine customs, working with Aborigine performing artists in triads and larger groups to facilitate trust, and in conferring with her clients regarding the relevance of strategies so as to support performance enhancement within the bicultural context. Affirming the importance of performer adaptation in relation to Canadian 
Aboriginal athletes (another marginalized indigenous culture), a Canadian Olympian of Aboriginal descent shared the following wish with her mixed Aboriginal and White mainstream audience from her vantage point as an athlete: "Sports psychology and a sports psychologist that will understand you, coming from that community, coming from your reality ... that would be my dream" (Waneek Horn-Miller as cited in Brant et al., 2002, p. 67). What Horn-Miller wished for was someone who could understand her as an Aboriginal athlete and consequently assist with the multicultural adaptation challenges she encountered performing in mainstream elite sport settings. Clearly, Horn-Miller's challenges assimilating within her national team were at the forefront of her thoughts when she reflected on experiences in the mainstream during the 2002 North American indigenous games.

Schinke and colleagues (2006) were among the first to formally consider athlete adaptation in elite sport with participants at the margins, doing so with elite Aboriginal participants pursuing sport in Canadian mainstream culture. Mainstream researchers collaborated with Aboriginal coresearchers to depict the athletes' cultural experiences. Semistructured interviews were employed with the athletes and thematic analysis was followed to organize the data, with verification and consensus from the coresearchers. It must be noted that despite what was found (below), the methods employed in the project lacked cultural sensitivity (Schinke et al., 2008). For example, individual interviews (one-on-one meetings with strangers) are a foreign strategy among Canadian Aboriginal peoples. Despite flaws in method, the authors found that the Aboriginal athletes' experiences were similar to Fiske's (2004) core motives, despite differences in terminology. Consider the following comparisons with the Aboriginal terms in italics and the parallel adaptation core motive in parentheses: (a) making the commitment to persist in mainstream sport (self-enhancement), (b) learning about the structure of mainstream sport (understanding), (c) self-managing their athletic development (control), (d) gaining acceptance among peers (trusting and belonging), and (e) resisting the environment (control).

Most recently, Schinke, Gauthier, Dubuc, and Crowder (2007) sought to verify and contextualize Fiske's (2004) core motives in a cross-cultural study on National Hockey League (NHL) players attempting adaptation during promotion, retention, or relocation. Using archival data, the authors considered players representing European, Canadian mainstream, and Canadian Aboriginal cultures. As only the latter group pertains to the present report, the adaptation substrategies derived from Canadian Aboriginal athletes are considered. Regardless of experience, the Canadian Aboriginal players spoke of assertiveness, a control strategy employed when demonstrating positive belief in their abilities. Belonging was also emphasized across participants through the support of community members in their hometown as well as the city hosting the NHL team. Increased physical effort and incessant learning were deemed necessary for those attempting to improve their abilities (self-enhancement) to be promoted, maintain a roster spot in the present team, or earn a roster spot after relocating. Among those players striving to maintain a roster spot, developing reciprocal cultural understanding in their teams was also identified. Furthermore, trusting others such as coaches, teammates, 
and The Creator (God) were regarded as helping maintain roster spots in the NHL. Clearly, NHL athletes perform at a higher level than the community-level reserve participants considered herein.

\section{Purpose of the Study}

As part of a larger research initiative developed to refine community sport programs beginning with Wikwemikong Unceded Indian Reserve, the community coauthors (a sport and recreation director, an elite Aboriginal coach, a director of the Wikwemikong Youth Center, and two elders) identified struggles encountered by adolescent Aboriginal athletes traveling to compete off reserve as part of their sport experiences, in this case among the mainstream. While many talented Wikwemikong athletes travel to urban centers to compete as they progress through community sport programs, many have struggled with mainstream sport encounters. The community coresearchers indicated that off-reserve sport opportunities are associated with challenges, including unfamiliar cultural traditions in and through sport practice and being confronted with racism (see also Schinke et al., 2006). Therefore, the purpose of this article was to consider the adaptation challenges and strategies of adolescent Canadian Aboriginal athletes as they travel from their community to pursue sport competitions in the mainstream culture. The current study reflects the integration of cultural research strategies among the Wikwemikong members, with community coresearchers engaged throughout as partners and coauthors.

\section{Method}

Data collection and analysis integrated five aspects: (a) the community; (b) the research team; (c) TCs; (d) data collection and analysis protocols; and (e) trustworthiness.

\section{The Community}

Wikwemikong is located on the eastern side of Manitoulin Island in northeastern Ontario, Canada. It spans across Georgian Bay and Lake Huron with the reserve area totaling 55,781 hectares. The on-reserve population is more than 2,700 people, making Wikwemikong the largest of seven Aboriginal communities on Manitoulin Island. As the first permanent settlement on Manitoulin Island, Wikwemikong has retained much of its rich history and traditional culture. The community is recognized as Canada's only Unceded Indian Reserve, meaning that its people have not relinquished title of their land to Canada's government (Manitoulin Island, 2005).

\section{Researchers' Assumptions}

The present work was informed by the assumptions of the researchers. Two of the Aboriginal coauthors (Peltier, Enosse) with previous competition experiences performed 
off reserve nationally in ice hockey and track and field, respectively. In addition, the elders guiding the project have traveled off reserve to support children and grandchildren at competitions. The adaptation struggles identified by the community authors as a group included fear of fitting into mainstream sport contexts and racism from mainstream athletes, coaches, and parents. With a shared view among the Aboriginal coauthors, it was suggested that the larger project pertaining to youth sport involvement in Wikwemikong also forefront questions pertaining to adolescent adaptation off reserve at sport competitions in the mainstream. The intent was to better understand such challenges and, from what was learned, share the teachings with aspiring youth sport participants. The mainstream coauthors have previously researched the adaptation process of elite Aboriginal athletes and so were also curious of the challenges and consequent strategies employed by adolescent sport participants.

\section{Initial TCs}

On the project's clearance from the university's research ethics board and Wikwemikong's Band and Council, two general TCs (15 participants per circle) were held in Wikwemikong to begin the project (see Table 1). The TC1 and TC2 were open for all community members to participate and share their thoughts regarding adolescent athlete sport participation. Within Wikwemikong, TCs are a traditional way of bringing people together with the intent of sharing knowledge, experiences, and feelings (see also Picou, 2000; Running Wolf \& Rickard, 2003). Furthermore, TCs exemplify the collective nature of the intended culture, and the process is designed to manifest in collaborative discussion. Community members were contacted to participate in initial TCs through posted notices. Both circles included youth, present and former athletes, family members, teachers, coaches, sport and recreation staff, and community elders. Participants were seated in a circular formation and asked one at a time to respond to questions. A stone was passed around the circle in a clockwise direction (in keeping with Wikwemikong tradition) with its possession indicating a person's turn to speak (see Picou, 2000; Running Wolf \& Rickard, 2003, for a review). Participants were given the opportunity to respond to each question in as much depth as they felt comfortable while also having the option to decline responding at any point in time. The TCs were concluded when all participants felt there was no more information to be added.

\section{Data Collection and Analysis Protocols}

As suggested by the Wikwemikong coresearchers, five additional TCs were later sought to enrich the initial data collection and target the aforementioned youth cohorts. Each circle was led by a youth leader designated by the Wikwemikong coauthors. TCs with adolescents were held in Wikwemikong's elementary school and high school to seek input from youth by grade (i.e., one for Grades 7-8 [TC3], one for Grades 9-10 [TC4], and one for Grades 11-12 [TC5]). Eight to 10 youth participated 
Table I. Talking Circle (TC) Questions

General community talking circles and initial youth talking circles (TCI-TC4)

I. When you think about activity, who is the most influential person in your life and why?

2. Are there things that get in the way of your sport and activity involvement?

3. Who makes it possible for you to be involved in an activity? What do/did they do and why?

4. What activities do/did you like and why?

5. What are the benefits of being involved in sport and activity?

6. What are the down sides to activity involvement (if there are any)?

Final youth talking circles (TC5-TC6)

I. Who makes it possible for you to be involved in a sport or activity?

2. What do grandparents do to get you involved in sport? Parents? Other family members?

3. What experiences have you had when playing sports outside of the community?

4. Have you ever experienced or witnessed any discrimination through your sport activities outside of Wikwemikong?

5. Have you ever experienced or witnessed discrimination in sport when athletes came to compete in Wikwemikong?

6. If you did experience or witness racism, what were some of the responses?

7. Do you know what a "maano" attitude is? Have you ever used this approach to racism?

8. Do you have any role models from outside the community? Why are they your role model?

9. Do you have any role models in the community? Why are they your role model?

in each TC. The questions posed during TCs 3 to 5 replicated those used in the initial community TCs (previous section) regarding broader themes of youth sport programming and adherence. However, questions utilized in the final two circles held in the high school (TC6 with Grades 9-10, TC7 with Grades 11-12) were refined through community research meetings, wherein emergent themes were pursued and thin areas in the data set were thickened with further exploration. Questions relevant herein pertained to experiences participating in sport outside of the community, cross-cultural encounters in sport, and responses to cross-cultural challenges (see Table 1). Throughout the 3-year project, at least one meeting per month was held in Wikwemikong to discuss questions and analyses and also the application of what was gleaned in the community (see Schinke et al., 2008).

Data analyses. Data were analyzed inductively based on guidelines authored by Schinke et al. (in press). First, each TC was transcribed verbatim followed by a thorough review of the document (i.e., misspelling, missing words). Second, provisional terms were assigned throughout the document by a Wikwemikong coresearcher, who 
was also a university student, with support from two graduate students and the first author. Third, the anecdotes were compared and contrasted among the student researchers until representative definitions for each theme were created by consensus. Fourth, the data were presented to the community coresearchers during a daylong discussion, and the terms and thematic analysis was refined by consensus in Wikwemikong. Consensus amongst the community coauthors was facilitated by providing flip chart pages, with each general theme featured on a distinct page. Subsequently, posted notes were employed to nest subthemes within each general theme. Throughout the discussion, the community members considered the classification scheme and repositioned themes and subthemes until all Wikwemikong members were satisfied. Community involvement also enhanced the relevance of coding initially proposed by the Wikwemikong student author, thus ensuring an indigenous coding method (e.g., Schinke et al., in press; see also Patton, 2002). Indigenous codes were labels developed and defined by the Wikwemikong during research team meetings.

\section{Trustworthiness}

Three of Maxwell's (2002) validity criteria for qualitative inquiry aligned with the study comprised of descriptive validity, interpretive validity, and theoretical validity. In addition, transactional and transformational validity (see Cho \& Trent, 2006) were integrated in the method, given the importance of praxis as part of the project.

Maxwell's guidelines. For descriptive validity, all TCs and community meetings were recorded using two audio recorders to avoid malfunction and missing data. The transcribers reviewed each recording prior to transcription, transcribed it verbatim, and then compared the transcript to the audio recording to enhance accuracy. For interpretive validity, ongoing collaboration with the Wikwemikong researchers enhanced the depiction of relevant topics from Wikwemikong's standpoint. For example, the coauthors provided contextual knowledge to facilitate the development of appropriate questions, assist with the data collection-analysis process, and engage in coauthoring. The theoretical validity of the current project was supported in two ways. First, the anecdotes were coded by the Wikwemikong student researcher in collaboration with two graduate students. Second, the preliminary analysis was presented to the Wikwemikong coresearchers to modify categorization and labels. Changes were discussed and incorporated with consensus among the coresearchers in Wikwemikong.

Cho and Trent's (2006) guidelines. Various steps were built into the research project to enhance transactional validity. First, TC questions were designed so follow-up questions could be asked to achieve mutual understanding. Second, at each stage of analysis, community coresearchers (who were also leaders in the TCs) were consulted to verify that interpretations were in accordance with the values and beliefs of Wikwemikong. In addition, a university student from Wikwemikong was employed to assist with the data analysis and interpretation to affirm cultural values. Transformational validity was also pursued. First, our team has implemented training opportunities for youth 
leaders as well as sport staff. Separate leadership training manuals exist for youth and for adult sport staff that are delivered semiannually through experiential educational opportunities. The intent is to develop community leaders and support the engagement of Aboriginal youth through sport and activity. Pertaining to this submission, leadership skills include discussions pertaining to buffering strategies for the youth who compete off reserve. The intent this coming year is to have the youth leaders deliver the information to aspiring youth from their age cohort through youth leadership meetings. Second, the research process has become an opportunity for the community authors to lead research relevant to their community and present the work to the North American Aboriginal and mainstream populations. Third, our collaboration has contributed to positive relationships among the project team, leading to increasingly relevant community projects. The above transformative guidelines accord with decolonizing methodologies, where the focus is on building skills among (and from within) a marginalized people (see Canadian Institutes of Health Research, 2007; Smith, 1999).

\section{Results}

The larger database comprised 996 anecdotes, with 114 belonging within the boundaries of the present submission. Three themes were identified: (a) challenges pursuing sport outside of the Aboriginal community in advance of bicultural encounters, (b) challenging bicultural encounters in Canadian mainstream sport contexts, and (c) responses to racism and discrimination that the Wikwemikong coresearchers have chosen to forefront through a closer consideration of control strategies (see Table 2). Sample anecdotes selected by the Wikwemikong coresearchers by consensus through monthly meetings are used to contextualize each theme, with a meeting or TC reference following the anecdote (e.g., "TC1" refers to TC one, while "M3" refers to meeting three).

\section{Challenges Pursuing Sport Outside of the Aboriginal Community in Advance of Bicultural Encounters}

Community members highlighted challenges that were experienced in advance of bicultural encounters in the mainstream. Though the immediate overarching theme was supported by only a few responses, likely due to the focus on within reserve shortcomings, it was suggested by the Wikwemikong coauthors that the category remain as a stand-alone category. Adaptation-related challenges for the young athletes have included understanding the limited off-reserve support when traveling and fear of negative cultural representation.

Limited off-reserve support. Community members were quick to point out a difference in the structuring of support networks for athletes who compete within their cultural community versus in mainstream sport contexts. For Wikwemikong athletes, intricate webs of support exist on reserve due to proximity, including family members, elders, recreation staff, and members of the larger community who attend competitions 
Table 2. Adaptation Reflections of Wikwemikong Athletes Pursuing Sport in Mainstream Contexts

\begin{tabular}{|c|c|c|c|}
\hline $\begin{array}{l}\text { Adaptation } \\
\text { subthemes }\end{array}$ & Anecdotes & $\begin{array}{c}\text { Adaptation theme } \\
\text { (total anecdotes }=114 \text { ) }\end{array}$ & $\begin{array}{c}\text { Multicultural equivalent } \\
\text { within adaptation } \\
\text { theme }\end{array}$ \\
\hline $\begin{array}{l}\text { Limited off reserve } \\
\text { support }\end{array}$ & 6 & $\begin{array}{l}\text { Challenges pursuing } \\
\text { sport outside of the } \\
\text { Aboriginal community } \\
\text { in advance of bicultural } \\
\text { encounters (9) }\end{array}$ & Belonging \\
\hline $\begin{array}{l}\text { Fear of negative } \\
\text { cultural } \\
\text { representation }\end{array}$ & 3 & & $\begin{array}{l}\text { Belonging; } \\
\text { understanding }\end{array}$ \\
\hline $\begin{array}{l}\text { Mainstream sport } \\
\text { organizations, } \\
\text { politics and finance }\end{array}$ & 20 & $\begin{array}{l}\text { Challenging bicultural } \\
\text { encounters in } \\
\text { Canadian mainstream } \\
\text { sport contexts (49) }\end{array}$ & Belonging; trust \\
\hline $\begin{array}{l}\text { Mainstream } \\
\text { opponents and } \\
\text { racism }\end{array}$ & 15 & & Control; understanding \\
\hline $\begin{array}{l}\text { Mainstream } \\
\text { administrators and } \\
\text { racism }\end{array}$ & 14 & & Belonging \\
\hline The maano response & 24 & $\begin{array}{l}\text { Responses to racism } \\
\text { and discrimination }(56)\end{array}$ & Control \\
\hline The active response & 32 & & Control; understanding \\
\hline
\end{tabular}

(see Schinke \& Hanrahan, 2009). Aboriginal support was regarded as less accessible when visiting mainstream communities, leaving the athletes without a sense of belonging. One community member explained,

The support helps to produce a sense of belonging which prevents that feeling of being isolated from loved ones. In some cases, these athletes have the passion and the drive [for sport], but they hesitate when they have an opportunity outside the community because that feeling of not belonging is so strong. (TC1)

Responding to the potential loss of community support off reserve, one parent proposed the following solution that aligned with belonging:

The community can continue to provide support through the role modeling sponsorship (a system where community-designated elite athletes share their stories and strategies with the youth during formal meetings and presentations) that Wikwemikong Recreation Department provides annually. The community can also provide news feed to the Manitoulin Expositor (newspaper) 
column that can highlight the youth who are engaged in sports outside of the community. (TC2)

Fear of negative cultural representation. In Wikwemikong, community members share a strong sense of responsibility to support adolescent sport participants in their development. Given their emotional investment, community members feel a strong sense of pride in the successes of their athletes, viewing them as cultural successes. It should be noted that on-reserve youth have been documented generally as an at-risk population, with rates of type 1 diabetes, obesity, substance misuse, and incarceration at least five times higher than the national average (Aboriginal Diabetes Initiative, 2004; Health Council of Canada, 2007). Although bestowing a sense of honor on the athletes who represent Wikwemikong is being supportive, it also adds to a worry among some youth of potential failure. One community coach voiced the following:

When Native athletes are playing with non-Native athletes, they have to try even harder because of our history ... So, when they're losing, they see it as a cultural failure as opposed to a game that has been lost. (TC1)

Community members highlighted the importance for athletes to reflect (understanding) on the community's pride and support (a form of belonging) behind them regardless of outcome. A sport staff member spoke of community support for youth competing in sport:

In the past, there was recognition by the Chief and Council for youth who have participated in elite sport whether the individual achieved a medal or championship or not. This was part of the Chief and Council Oath of Office Ceremony, and therefore only took place every second year. It would be advisable to the elected leadership that the ceremony takes place annually. It is important to be recognized for accomplishments and hard work achieved throughout each year. (TC2)

\section{Challenging Bicultural Encounters in Canadian Mainstream Sport Contexts}

There were a number of challenges revealed pertaining to mainstream sport organizations, opponents, and administrators. Community members highlighted the need for effective support networks to be developed to assist with mainstream encounters.

Mainstream sport organizations, politics, and finances. Community members discussed political influences as a concern when encountering mainstream sport organizations. One parent recalled a politicized selection process for her daughter's competitive team, stating as follows: "The association had to be mindful of how many girls that they were picking from outside of [city] because they knew that they would have to face the political backlash for taking so many players outside their district" (M3). Consequently, 
some Aboriginal athletes felt that their talent was ignored and displaced to the margins, due to undercurrents of political agendas within mainstream organizations.

Also compounding the challenge of seeking out mainstream sport experiences were the financial challenges posed by traveling at least $200 \mathrm{~km}$ to the closest urban center. The added expense required in the support of off-reserve travels was a matter of rising fuel costs and accommodations for parents, often on fixed incomes. For sport opportunities off reserve then, athletes were said to rely heavily on the emotional and financial support of family and community members (manifestations of belonging). As potential strategies to overcome financial challenges, a coach from the community discussed available venues of support when athletes travel off reserve:

You're looking at the family, the immediate family. You're looking at extended family. You're looking at Chief and Counsel. They're all connected; they all have a vested interest in the community members. Then you have outside agencies, Native outside agencies that you connect with. Those are all supporting networks. There are non-Native agencies also but that athlete will not have a connection to that outside agency. (TC1)

Mainstream opponents and racism. Community members discussed the challenges associated with competing against athletes from the mainstream culture who were quick to yell out racist slurs. One Grade 11 student recalled an experience from a hockey tournament: "I was called names from the fans and opponents on the other teams. I was called a dirty Indian, a squaw, and a savage" (TC6). Other athletes shared stories of physical altercations (i.e., control attempts through physical means) that were attributed to name calling from athletes as well as fans belonging to the mainstream culture. Another high school student spoke of an out-of-town hockey game: "Every time we were in the penalty box, fans would throw (stuff) at us every time we got off the ice, at our whole team in general" (TC6). A recreation center staff member suggested the importance of managing cultural insensitivity and commented on the current status of racism in her region:

It has a public perception now that it's not tolerable; in the past it was. They're trying to make it shift but it's still kind of there. It's under the surface, people are trying to be a little more covert about their comments and make sure nobody hears them. (M3)

Mainstream administrators and racism. Community members described several negative encounters with event organizers, administrators, and referees in competition environments. A parent told the story of a community athlete who had competed in a provincial championship and had been called names. She emphasized how a complaint was filed on the athlete's behalf, "but the organizers just swept it underneath the rug" (M5). Referees were also identified in some instances of discrimination, as a Grade 10 student athlete recalled: "The referees in the game were screaming and 
swearing at us, and our coaches and fans didn't think that the refs were treating us well" (TC5). Athletes and their parents discussed feeling ignored by sport authority figures in mainstream contexts and indicated the importance of teammate support (i.e., belonging) in helping the athletes work through and move past racism, and remain focused on their goals. One parent suggested the following: "There is a need to further sensitize the players and the coaching staff by providing more emphasis on respect for the game and the opponents" (TC2). Given the extent to which racism and discrimination were viewed as challenges for adolescent Aboriginal athletes in bicultural encounters in Canadian mainstream sport contexts, the following major section is devoted toward discussing important adaptation strategies to overcome these challenges.

\section{Responses to Racism and Discrimination}

Both a maano (Wikwemikong term for passive) and a more active approach were regarded as control responses to racism. By either passively ignoring people who are being racist or actively telling them that their behavior will not be tolerated, the Aboriginal athletes have attempted to exert control in challenging mainstream circumstances.

The maano (passive) response. When exposed to racism and discrimination within the mainstream context, community members described using passivity (a form of control), termed the maano response. An elder stated, "I ran into discrimination, but it's not something that kept me back (reflecting on experiences as a child in sport). I just stayed away from those people. I guess I was of that maano generation" (M3). When prompted to describe the term maano, a sport programming staff member explained, "It's telling people to just leave it alone rather than getting into a heated argument" (M3) when one cannot affect change. Community members said they would attempt to diffuse and terminate the situation by ignoring the individuals confronting them. For many athletes, a passive approach was used to disengage from confrontational behavior and risk jeopardizing their own athletic success.

The active response. Although a passive maano approach was advocated as an effective response for dealing with racism and discrimination, community members also described instances when active responses were utilized. One parent recalled the following experience that reflects the pursuit of control through teaching sensitivity to a mainstream attendee:

At a hockey game, one lady shouted "That's how you Indians are!" at us and we were like, "What? Did we hear that right?" So one of the parents walked out of the arena, found the lady and said "There's no need for comments like that around here. You're an adult and you shouldn't be making racist comments like that." (M3)

In another case, a former elite hockey player recalled a personal experience when he had been subjected to racist remarks from an opposing team and was later contacted by a league official about the incident. Again, the attempt was to exert control and convey understanding: 
He said, "What do you want done about it?" And I said, "I don't know. What can be done?" He replied, "Anything can be done." So I remembered that our team was working with a kids sport program to help inner-city youth and a lot of them were First Nations kids. So I told him to get that team and coach to go and volunteer at an inner-city school in their city. (M3)

Community members have indicated that while a maano approach is often effective in dealing with racism, it sometimes is not seen as enough, and a more active response is required. By actively responding, athletes attempt to assert themselves and exert control in the context.

\section{Discussion}

Our project team elicited the adaptation challenges and strategies of Canadian Aboriginal athletes from Wikwemikong as they considered how their community's youth pursue sport opportunities in the mainstream. From what was learned, there are parallels with the earlier general adaptation literature (see Table 2). Extending the cognitive adaptation theory of Taylor (1983), Fiske (2004) proposed the following five motives as vehicles to effective adaptation: controlling, self-enhancement, understanding, belonging, and trust. Controlling was evident in our study through athletes' responses to racism and discrimination. Precisely, the athletes aimed to diffuse racism and prevent escalation (i.e., active response), while also controlling their own responses of anger (i.e., maano response). Undeniably, the acquisition of control strategies would allow for self-enhancement (i.e., athletic and personal development) through ongoing adaptive responses mastered in mainstream sport contexts. Understanding was evident when the athletes pursued sport outside of their cultural community and then encountered the challenges posed by being an Aboriginal community member in a mainstream sport context with excluding, and also, racist aspects. Precisely, understanding included active responses when the Wikwemikong asserted their views with mainstream members and passive responses when it was believed that the only understanding to be achieved was self-understanding. The garnering of a community support network was a recurrent adaptation strategy identified by the Wikwemikong, affirming the core motives of belonging and trust. Through community social support, the athletes felt that they belonged to Wikwemikong and that the cultural community would support them through adaptation challenges. Furthermore, there was a belief that family and community would be consistent in their support, leading to enhanced trust.

Clearly, general adaptation motives were evident in the participants' words, though it should be noted that questions of adaptation were not easily resolved. For example, efforts at control reflected the dialectic between self-management and external control attempts, with neither choice being regarded as the consistent answer. The motives of belonging and trust were also found throughout the participants' responses, and interestingly they did not always have a positive connotation. There was some indication that the aspiring athletes felt a level of responsibility to Wikwemikong and also a 
concern of misrepresenting the community through subpar performances. Beyond community pressures, the athletes encountered cultural challenges such as racist comments when they pursued self-enhancement. Consequently, though adaptation attempts are typically adaptive because they tend to propel people forward, when one is from a marginalized culture, there is the inherent risk of maladaptive encounters while one seeks developmental opportunities.

The present work also aligned with previous sport and activity adaptation research. Tenenbaum and colleagues (2003) considered elite cyclists and found that effective adaptation strategies included positive affect, low levels of contextual anxiety, strong feelings of hope, clear thinking, and a strong sense of social support. Similar trends also held with Schinke and colleagues' $(2006,2007)$ studies with elite-level Aboriginal performers when athletes identified the employment of self-regulatory behaviors and community resources. Extending the work of Tenenbaum and colleagues, Schinke and colleagues learned that adaptation to challenges and consequent strategies among Aboriginal athletes are in part a matter of culture (for the Aboriginal sport participants and also the mainstream members they encounter off reserve). The bicultural aspects add to the complexity of what is to be understood and also how understanding is achieved (actively with others or passively within oneself). Matters of control also extend beyond sport performance to contextual challenges posed by a history of marginalizing experiences. Also adding to the challenges encountered, as denoted also by HornMiller (cited in Brant et al., 2002) and Hanrahan (2004), are matters of trust when entering into an unfamiliar cultural community and a perceived pressure of effectively representing the community of origin. In the present case, many off-reserve challenges were described for adolescent Aboriginal athletes at the preelite level, ones that could continue to be present for elite Aboriginal athletes in adulthood. Worth considering then are the benefits and risks associated with off-reserve sport encounters in the mainstream and how what is learned in terms of benefits and also risks can enhance (or not) adaptation during a formative time (i.e., preadulthood).

The present work also extended previous CSP contributions. Within earlier work, there was a call by Ryba and Wright (2005); Fisher et al. (2003); and Kontos and Breland-Noble (2002) for research and practice that reflects the intended culture. The call for CSP research has gained traction of late with a published compilation by Schinke and Hanrahan (2009). Consistent across CSP contributors has been the call for culturally reflexive practice in place of a monocultural approach (i.e., previously cross-cultural patterns across athletes were sought). The present work is an attempt at cultural reflexivity as affirmed through a participatory research project, with the integration of research practices relevant among the Wikwemikong. The present work is not intended as "Aboriginal research" but rather as a catalytic work with lines of questioning and research strategies that encourage voices from the intended community. Arguably, our present work provides a more reliable description of adaptation processes among adolescent sport participants from the intended community than reports that entirely reflect mainstream methodologies, such as Schinke et al. (2006). Equally relevant, and in keeping with Canadian Institutes of Health Research (2007) guidelines 
for Aboriginal research (see also Smith, 1999), is also what might be achieved through research projects such as the present collaboration. At the forefront of our work are aspects of praxis (see Blodgett et al., 2008) and transformational validity (see Cho \& Trent, 2006), such as the promotion of the Wikwemikong coresearchers, and also the creation of applied strategies for aspiring youth as integral parts of the overall research project. Our strategies are intended to spur immediate transformation, beyond the mainstream benefits derived through academic research, such as knowledge generation and proliferation.

\section{Conclusions and Implications}

Collaborations among the research team have enabled the Wikwemikong coresearchers to move the current project forward toward community integration through applied sport programming. Based on the recommendations of community members, leadership and coaching training programs are currently being offered in Wikwemikong to educate young athletes who may one day consider pursuing sport opportunities in the mainstream culture. The training programs include community-based case studies, cultural traditions, and group discussions. Through effective dissemination and support, it is hoped that young Aboriginal athletes will garner the personal and community resources to engage effectively in sport opportunities off reserve in the mainstream.

From this project, we recommend that a CSP (culturally reflexive) approach be utilized in future adaptation research with more cultures and that research be conducted with other marginalized communities to broaden the sport literature. Through such efforts, researchers and practitioners will gain a deeper understanding of the adaptation process and how to work effectively within cultural parameters. Furthermore, we suggest that researchers enlist community members as partners in research and resource such individuals as the experts of their experiences. When working with marginalized populations, it is also important to transition research findings into a community-relevant initiative as a means of supporting positive social change and contributing to the development of positive relationships among cultures.

\section{Acknowledgment}

The authors would like to thank the Social Sciences and Humanities Research Council of Canada for their support of the study as an Aboriginal Program (SSHRC No. 856-2005-0030). This project would not have been possible without the support of Wikwemikong Unceded Indian Reserve.

\section{Declaration of Conflicting Interests}

The author(s) declared no potential conflicts of interest with respect to the authorship and/or publication of this article.

\section{Funding}

The author(s) received no financial support for the research and/or authorship of this article. 


\section{References}

Aboriginal Diabetes Initiative. (2004). Introduction. Retrieved March 22, 2007, from http:// www.hc-sc.gc.ca/fnihb/cp/adi/introduction.htm

Blodgett, A. T., Schinke, R. J., Fisher, L. A., Wassengeso-George, C., Peltier, D., Ritchie, S., et al. (2008). From practice to praxis: Community-based strategies for Aboriginal youth sport. Journal of Sport \& Social Issues, 32, 393-414.

Brant, R., Forsyth, J., Horn-Miller, W., Loutitt, J., Sinclair, C., Smith, M., et al. (2002). North American indigenous games sport research panel. In R. Brant \& J. Forsyth (Eds.), 2002 North American Indigenous Games Conference Proceedings (pp. 67-70). Winnipeg, Canada: University of Manitoba Press.

Canadian Institutes of Health Research. (2007). CIHR guidelines for health reseach involving Aboriginal people. Ottawa, Canada: Author.

Cho, J., \& Trent, A. (2006). Validity in qualitative research revisited. Qualitative Research, 6, 319-340.

Fisher, L. A., Butryn, T. M., \& Roper, E. A. (2003). Diversifying (and politicizing) sport psychology through cultural studies: A promising perspective. Sport Psychologist, 17, 391-405.

Fiske, S. T. (2004). Social beings: A core motives approach to social psychology. Danvers, MA: Wiley \& Sons.

Hanrahan, S. J. (2004). Sport psychology and indigenous performing artists. Sport Psychologist, $18,60-74$.

Health Council of Canada. (2007). Aboriginal health 2006: Annual report. Available from http://www.healthcouncilcanada.ca

Kontos, A. P., \& Breland-Noble, A. M. (2002). Racial/ethnic diversity in applied sport psychology: A multicultural introduction to working with athletes of color. Sport Psychologist, 16, 296-315.

Manitoulin Island. (2005). Visit Wikwemikong. Retrieved November 21, 2007, from http://www .manitoulin-island.com/wikwemikong/

Maxwell, J. A. (2002). Understanding and validity in qualitative research. In A. M. Huberman \& M. B. Miles (Eds.), The qualitative researcher's companion (pp. 37-63). Thousand Oaks, CA: Sage.

Patton, M. Q. (2002). Qualitative research and evaluation methods (3rd ed.). Thousand Oaks, CA: Sage.

Picou, J. S. (2000). The "talking circle" as sociological practice: Cultural transformation of chronic disaster impacts. Sociological Practice: A Journal of Clinical and Applied Sociology, 2, 77-97.

Running Wolf, P., \& Rickard, J. A. (2003). Talking circles: A Native American approach to experiential learning. Multicultural Counseling and Development, 31, 39-43.

Ryba, T. V., \& Wright, H. K. (2005). From mental game to cultural praxis: A cultural studies model's implications for the future of sport psychology. Quest, 57, 192-212.

Schinke, R. J., Gauthier, A. P., Dubuc, N. G., \& Crowder, T. (2007). Understanding athlete adaptation in the National Hockey League through an archival data source. Sport Psychologist, 21, 277-287. 
Schinke, R. J., \& Hanrahan, S. J. (Eds.). (2009). Cultural sport psychology. Champaign, IL: Human Kinetics.

Schinke, R. J., Hanrahan, S. J., Eys, M. A., Blodgett, A., Peltier, D., Ritchie, S., et al. (2008). The development of cross-cultural relations with a Canadian Aboriginal community through sport psychology research. Quest, 60, 357-369.

Schinke, R. J., Michel, G., Gauthier, A., Danielson, R., Pickard, P., Peltier, D., et al. (2006). Adaptation to the mainstream in elite sport: An Aboriginal perspective. Sport Psychologist, 20, 435-448.

Schinke, R. J., Peltier, D., Hanrahan, S. J., Eys, M. A., Yungblut, H., Ritchie, S., et al. (2010). The progressive move toward indigenous strategies among a Canadian multicultural research team. International Journal of Sport and Exercise Psychology, 7, 309-322.

Smith, L. T. (1999). Decolonizing methodologies: Research and indigenous peoples. Dunedin, New Zealand: University of Otago Press.

Taylor, S. E. (1983). Adjustment to threatening events: A theory of cognitive adaptation. American Psychologist, 38, 1161-1173.

Tenenbaum, G., Jones, C. M., Kitsantis, A., Sachs, D. N., \& Berwick, J. P. (2003). Failure adaptation: An investigation of the stress response process in sport. International Journal of Sport Psychology, 34, 27-62.

\section{Bios}

Robert J. Schinke is a full professor in the School of Human Kinetics at Laurentian University in Sudbury, Ontario, Canada. He works with graduate and doctoral students in topics that intersect sport psychology and cultural studies.

Amy T. Blodgett is a doctoral student in the Human Studies Program at Laurentian University in Sudbury, Canada. Her research and practical interests pertain to culturally reflexive approaches, where at presently she is part of a multicultural sport research team.

Hope E. Yungblut is a doctoral candidate in the Human Studies Program at Laurentian University, funded by the Social Sciences and Humanities Research Council of Canada. Her areas of interest include youth sport, gender, and qualitative methodologies.

Mark A. Eys is an associate professor and Canada research chair in group dynamics within the School of Kinesiology and Physical Education at Wilfrid Laurier University. He researches in the areas of group dynamics, leadership, and role clarity with both mainstream and cultural minority populations.

Randy C. Battochio is a doctoral student in the Human Studies Program at Laurentian University. His area of interest spans developmental and elite athlete adaptation. He is funded by Ontario Graduate Studies.

Mary Jo Wabano holds a leadership position in the Wikwemikong Youth Centre, where she develops youth programming for community and preelite Aboriginal youth on-reserve. 
Duke Peltier is the director of sport and recreation in Wikwemikong Indian Reserve. A former elite athlete, he is a member of Band and Council in his community.

Stephen Ritchie is an assistant professor, the adventure leadership coordinator, and a doctoral candidate in the School of Northern and Rural Health at Laurentian University in Sudbury, Ontario, Canada. He is presently engaged in Aboriginal research, and his interest is youth leadership training, using adventure leadership as the medium.

Patricia Pickard is a full professor at Laurentian University in the School of Human Kinetics. She has worked with the local Aboriginal community for many years as an educator, and her research interests pertain to feminist research, gender equity, and cultural reflexivity.

Danielle Recollet-Saikonnen is an undergraduate student at Laurentian University in the School of Native Human Services. She is a band member from Wikwemikong Unceded Indian Reserve. 